OPEN ACCESS

Edited by:

Laura Van Niftrik,

Radboud University, Netherlands

Reviewed by:

Felipe Cava

The Laboratory of Molecular Infection

Medicine Sweden, Sweden

Alexander John Frederick Egan,

Newcastle University, UK

${ }^{*}$ Correspondence:

André O. Hudson

aohsbi@rit.edu

${ }^{\dagger}$ These authors have contributed equally to this work

Specialty section:

This article was submitted to Evolutionary and Genomic

Microbiology,

a section of the journa

Frontiers in Microbiology

Received: 11 January 2016 Accepted: 07 March 2016

Published: 23 March 2016

Citation:

Naqvi KF, Patin D, Wheatley MS, Savka MA, Dobson RCJ, Gan HM,

Barreteau $H$, Blanot $D$,

Mengin-Lecreulx D and Hudson AO (2016) Identification and Partial

Characterization of a Novel UDP-N-

Acetylenolpyruvoylg/ucosamine

Reductase/UDP-N-

Acety/muramate:L-Alanine Ligase

Fusion Enzyme from

Verrucomicrobium spinosum DSM

4136 ${ }^{T}$. Front. Microbiol. 7:362.

doi: 10.3389/fmicb.2016.00362

\section{Identification and Partial} Characterization of a Novel UDP-NAcetylenolpyruvoylglucosamine Reductase/UDP-NAcetylmuramate:L-Alanine Ligase Fusion Enzyme from Verrucomicrobium spinosum DSM $4136^{\top}$

\author{
Kubra F. Naqvi ${ }^{1 \dagger}$, Delphine Patin ${ }^{2 \dagger}$, Matthew S. Wheatley ${ }^{1}$, Michael A. Savka ${ }^{1}$, \\ Renwick C. J. Dobson ${ }^{3,4}$, Han Ming Gan ${ }^{5,6}$, Hélène Barreteau ${ }^{2}$, Didier Blanot ${ }^{2}$, \\ Dominique Mengin-Lecreulx ${ }^{2}$ and André O. Hudson ${ }^{1 *}$
}

\footnotetext{
${ }^{1}$ Thomas H. Gosnell School of Life Sciences, Rochester Institute of Technology, Rochester, NY, USA, ${ }^{2}$ Institute for Integrative Biology of the Cell, CEA, CNRS, Univ Paris-Sud, Université Paris-Saclay, Orsay, France, ${ }^{3}$ Biomolecular Interaction Centre, School of Biological Sciences, University of Canterbury, Christchurch, New Zealand, ${ }^{4}$ Department of Biochemistry and Molecular Biology, Bio21 Molecular and Biotechnology Institute, The University of Melbourne, Parkville, VIC, Australia, ${ }^{5}$ Monash University Malaysia Genomics Facility, Monash University Malaysia, Selangor, Malaysia, ${ }^{6}$ School of Science, Monash University Malaysia, Selangor, Malaysia
}

The enzymes involved in synthesizing the bacterial cell wall are attractive targets for the design of antibacterial compounds, since this pathway is essential for bacteria and is absent in animals, particularly humans. A survey of the genome of a bacterium that belongs to the phylum Verrucomicrobia, the closest free-living relative to bacteria from the Chlamydiales phylum, shows genetic evidence that Verrucomicrobium spinosum possesses a novel fusion open reading frame (ORF) annotated by the locus tag (VspiD_010100018130). The ORF, which is predicted to encode the enzymes UDP-N-acetylenolpyruvoylglucosamine reductase (MurB) and UDP-N-acetylmuramate:L-alanine ligase (MurC) that are involved in the cytoplasmic steps of peptidoglycan biosynthesis, was cloned. In vivo analyses using functional complementation showed that the fusion gene was able to complement Escherichia coli murB and murC temperature sensitive mutants. The purified recombinant fusion enzyme (MurB/ $C_{V s}$ ) was shown to be endowed with UDP-N-acetylmuramate:L-alanine ligase activity. In vitro analyses demonstrated that the latter enzyme had a $\mathrm{pH}$ optimum of 9.0, a magnesium optimum of $10 \mathrm{mM}$ and a temperature optimum of $44-46^{\circ} \mathrm{C}$. Its apparent $K_{m}$ values for ATP, UDP-MurNAc, and L-alanine were 470, 90, and $25 \mu \mathrm{M}$, respectively. However, all attempts to demonstrate an in vitro UDP- $N$-acetylenolpyruvoylglucosamine reductase (MurB) activity were unsuccessful. Lastly, Hidden Markov Model-based similarity search 
and phylogenetic analysis revealed that this fusion enzyme could only be identified in specific lineages within the Verrucomicrobia phylum.

Keywords: MurB, MurC, UDP-N-acetylenolpyruvoylglucosamine reductase, UDP- $N$-acetylmuramate:L-alanine ligase, fusion enzyme, bacterial cell wall, peptidoglycan, Verrucomicrobium spinosum

\section{INTRODUCTION}

Bacteria belonging to the Verrucomicrobia phylum are Gramnegative heterotrophic organisms that are generally found in soil and fresh water environments. The phylum is considered to have two sister phyla, Chlamydiae and Lentisphaerae (Cho et al., 2004). Members of the Verrucomicrobia are of interest due to their close evolutionary relationship to bacteria from the genus Chlamydia in addition to their unusual morphology of possessing wart-like and tube-like appendages that protrude from the cell membrane, commonly referred to as prosthecae (Wagner and Horn, 2006; McGroty et al., 2013). Most of the research that has been done with bacteria from this phylum has been done using Verrucomicrobium spinosum as the model organism. The bacterium was found to employ the type III secretion system and is pathogenic toward Drosophila melanogaster and Caenorhabditis elegans (Sait et al., 2011). In addition, research from our group recently demonstrated that the bacterium employs the L,L-diaminopimelate aminotransferase (DapL) pathway for the synthesis of meso-diaminopimelate involved both in the cross-linking of peptidoglycan (PG) and in lysine anabolism (Nachar et al., 2012; McGroty et al., 2013). Due to the morphological complexity and unusual cellular plan of $V$. spinosum, the synthesis of $\mathrm{PG}$ is of interest to our group given its close relationship to the pathogenic organisms from the genus Chlamydia. In addition, the recent discovery of $P G$ in Chlamydia has made this project more intriguing, given the fact that even though $\beta$ lactam antibiotics are effective against Chlamydia, definitive evidence of PG in Chlamydial species has been lacking until this recent discovery (Pilhofer et al., 2013; Packiam et al., 2015).

Cell wall PG (also named murein) is ubiquitous in the bacterial domain. The PG of bacteria is composed of tandem repeats of the sugars $\mathrm{N}$-acetylglucosamine (GlcNAc) and $\mathrm{N}$-acetylmuramic acid (MurNAc) cross-linked by a short peptide stem containing usually L-lysine or meso-diaminopimelate at the third position (Park, 1987; Vollmer et al., 2008). Due to its rigid structure and tensile strength, the PG has several overarching roles such as protecting the osmotic integrity of the cell in addition to maintaining the shape of the bacteria.

The synthesis of PG in bacteria occurs via a pathway that has three distinct steps: the cytoplasmic, membrane, and periplasmic steps. In the cytoplasmic steps, the nucleotide sugarlinked precursor UDP-MurNAc-pentapeptide is synthesized in a series of reactions catalyzed by the enzymes MurA, MurB, MurC, MurD, MurE, MurF, and Ddl (Figure 1) (Barreteau et al., 2008). The next steps in PG formation are the synthesis of the lipid precursor intermediates, undecaprenyl-diphospho-MurNAc-pentapeptide (lipid I) and
undecaprenyl-diphospho-MurNAc-(pentapeptide)-GlcNAc (lipid II), by the enzymes MraY and MurG, respectively; these reactions occur at the level of the cytoplasmic membrane (Bouhss et al., 2008). The ultimate steps in the pathway are the transglycosylation and transpeptidation reactions, characterized by the polymerization of the sugar-peptide units and their incorporation into the growing PG; these reactions take place in the extra-cytoplasmic space and are catalyzed by the penicillinbinding proteins (PBPs) (Figure 1) (Scheffers and Pinho, 2005).

The first three cytoplasmic steps of the PG synthesis pathway, which are the topic of this paper, are as follows. First, UDP$\mathrm{N}$-acetylglucosamine-1-carboxyvinyltransferase (MurA, EC 2.5.1.7) catalyzes the transfer of the enolpyruvyl moiety from phosphoenolpyruvate to the 3 -hydroxyl end of UDP-GlcNAc to produce UDP- $N$-acetylenolpyruvoylglucosamine (UDPGlcNAc-EP) (Figure 1) (Marquardt et al., 1992; Wanke et al., 1992). Then, UDP- $N$-acetylenolpyruvoylglucosamine reductase (MurB, EC 1.3.1.98) catalyzes the reduction of the enolpyruvyl moiety of UDP-GlcNAc-EP to lactyl ether to produce UDP- $N$ acetylmuramic acid (UDP-MurNAc) (Figure 2A) (Benson et al., 1993; Tayeh et al., 1995). Finally, UDP-N-acetylmuramate:Lalanine ligase (MurC, EC 6.3.2.8) catalyzes the third reaction, which consists in the addition of L-Ala to the carboxyl group of UDP-MurNAc to produce UDP-MurNAc-L-Ala (Figure 2B) (Liger et al., 1995; Falk et al., 1996; Gubler et al., 1996).

Here we report the identification and biochemical partial characterization of a novel MurB/C fusion enzyme from $V$. spinosum. While in vitro assays demonstrate that the enzyme is able to catalyze the ligase (MurC) reaction, attempts to demonstrate the reductase (MurB) activity in vitro were unsuccessful. Nevertheless, in vivo analyses demonstrated that the fusion gene is able to functionally complement two Escherichia coli strains that harbor mutations in the murB and murC genes. Given the facts that (i) the MurB and MurC enzymes are not normally fused and are encoded by separate ORFs as is the case of the two E. coli proteins (Pucci et al., 1992; Liger et al., 1995), and (ii) the PG biosynthesis pathway is essential and is only present in the bacterial domain, the identification and characterization of this unusual fusion enzyme involved in PG biosynthesis in $V$. spinosum, a close relative of the pathogenic organism Chlamydia, is intriguing. This study has the potential to contribute to the further understanding of the kinetic, physical and structural properties of enzymes involved in the synthesis of PG in order to facilitate the development and/or discovery of antibacterial compounds that are able to combat current and emerging bacterial infections and diseases, especially those that are deemed to be resistant to antibiotics that are currently used in a clinical setting. 


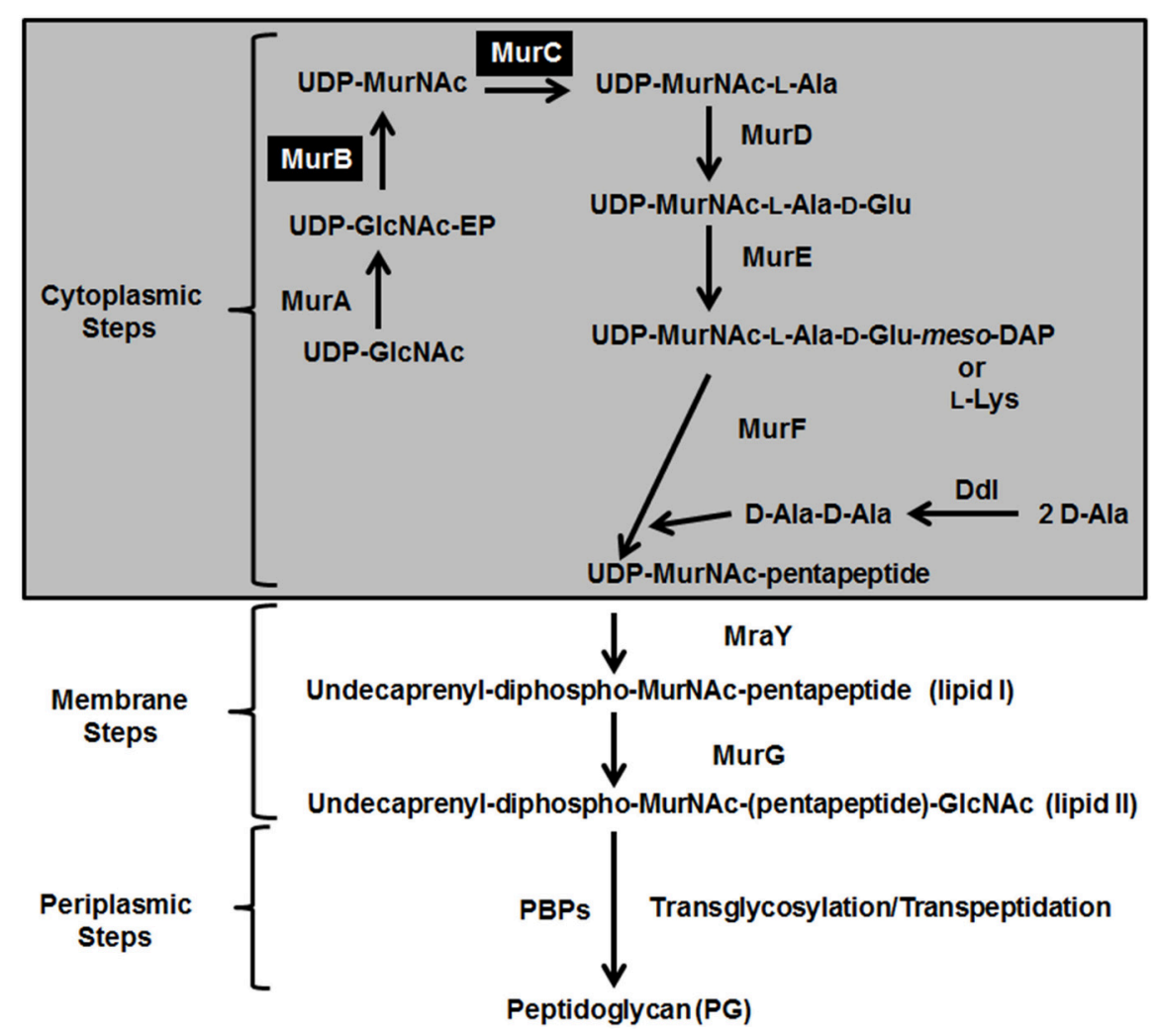

FIGURE 1 | Schematic representation depicting the three stages of PG biosynthesis in bacteria. The cytoplasmic, membrane, and periplasmic steps are shown. The abbreviations of the enzymes are as follows: MurA, UDP-N-acetylglucosamine 1-carboxyvinyltransferase; MurB, UDP-N-acetylenolpyruvoylglucosamine reductase; MurC, UDP-N-acetylmuramate:L-alanine ligase; MurD, UDP-N-acetylmuramoyl-L-alanine:D-glutamate ligase; MurE, UDP-N-acetylmuramoyl-Lalanyl-D-glutamate:2,6-diaminopimelate ligase or UDP-N-acetylmuramoyl-L-alanyl-D-glutamate:L-lysine ligase; MurF, UDP-N-acetylmuramoyl-tripeptide:Dalanyl-D-alanine ligase; Ddl, D-alanine:D-alanine ligase; MraY, phospho- $N$-acetylmuramoyl-pentapeptide transferase; MurG, undecaprenyl-diphospho- $N$ acetylmuramoyl-pentapeptide $\beta-N$-acetylglucosaminyl transferase; and PBPs, penicillin-binding proteins. The enzymatic activities theoretically carried by the MurB/C fusion enzyme from $V$. spinosum are shaded in black. UDP-GlcNAc-EP stands for UDP-N-acetylenolpyruvoylglucosamine.

\section{MATERIALS AND METHODS}

\section{Materials}

$\mathrm{L}-\left[{ }^{14} \mathrm{C}\right] \mathrm{Ala} \quad\left(5.99 \quad \mathrm{GBq} \cdot \mathrm{mmol}^{-1}\right)$ and $\mathrm{L}-\left[{ }^{14} \mathrm{C}\right] \mathrm{Ser} \quad(6.07$ GBq. $\mathrm{mmol}^{-1}$ ) were purchased from Perkin Elmer, $\left[{ }^{14} \mathrm{C}\right] \mathrm{Gly}$ (3.88 GBq. $\left.\mathrm{mmol}^{-1}\right)$ from CEA, and UDP- $\left[{ }^{14} \mathrm{C}\right] \mathrm{GlcNAc}(2$ GBq. $\mathrm{mmol}^{-1}$ ) from ARC Isobio. UDP- $\left[{ }^{14} \mathrm{C}\right]$ MurNAc was prepared according to published procedure (Bouhss et al., 2002). UDP-GlcNAc-EP was purchased from the BaCWAN facility.

\section{V. spinosum Growth Conditions/Plasmids and Strains used in this Study}

$V$. spinosum DSM $4136^{\mathrm{T}}$ was cultured in $\mathrm{R} 2 \mathrm{~A}$ medium supplemented with $5 \%(\mathrm{w} / \mathrm{v})$ artificial sea water at $26^{\circ} \mathrm{C}$ (Schlesner, 1987). The plasmids and strains used in this study are listed in Table 1.

\section{Domain Mapping of MurB/C $\mathrm{C}_{V s}$ Identification}

The protein family (Pfam) domains of $\mathrm{MurB} / \mathrm{C}_{V s}$ were identified using the Pfam server (http://pfam.sanger.ac.uk/) and (http://pfam.janelia.org/) (Finn et al., 2014). The conserved domain database (CDD) (http:// www.ncbi.nlm.nih.gov/ Structure/cdd/cdd.shtml) was used to identify the domains of MurB/C $V_{\text {s }}$ (Marchler-Bauer et al., 2015).

\section{Identification of Lineages Containing Fused MurB/C Protein and Phylogenetic Analysis of MurB and MurC Proteins}

Publicly available draft and complete genome sequences belonging to members of the phylum Planctomycetes, Verrucomicrobia, Chlamydiae, and Lentisphaerae (PVC) were downloaded from NCBI. The proteomes were re-predicted with Prodigal version 2.6 (Hyatt et al., 2010) and then used for phylogenomic tree construction with PhyloPhlAN (Segata et al., 2013). The manually curated database of protein families known as TIGFAMs was used to identify MurB (TIGR00179) and MurC (TIGR00182) proteins (Haft et al., 2003). The predicted whole proteomes were subjected to similarity search based on the hidden Markov model (HMM) profiles TIGR00179 and TIGR00182 using HMMsearch (-cut_tc option) (Eddy, 2011), and species containing unusual composition of MurB and MurC, i.e., fused MurB/C, missing MurB, and/or missing MurC, were 


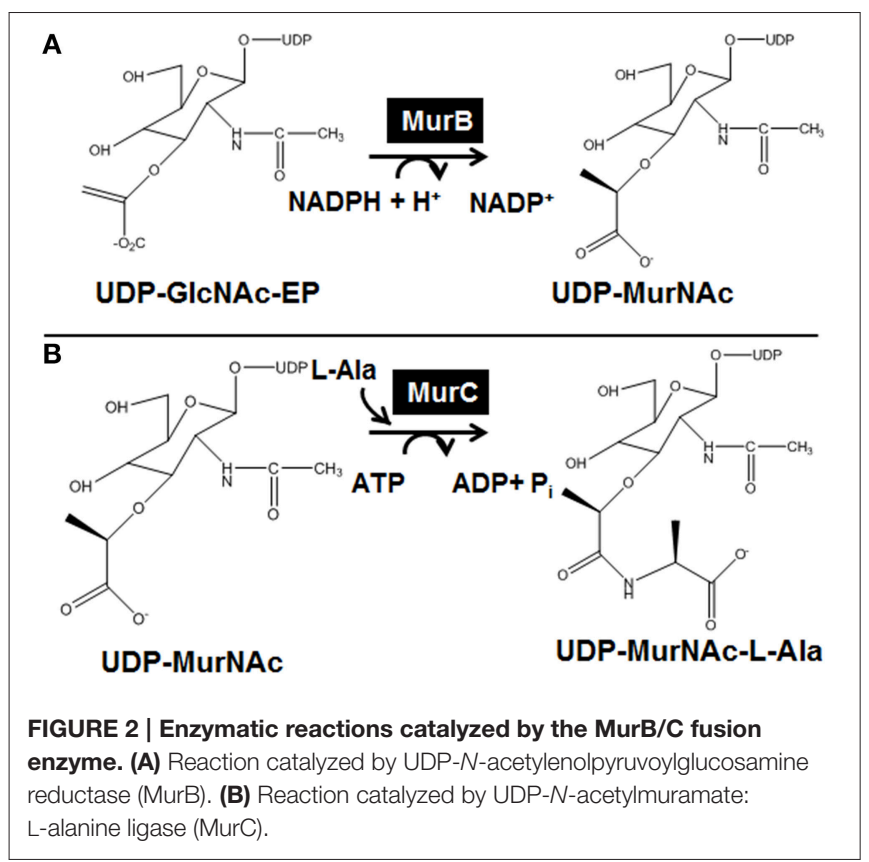

annotated in the constructed species tree. Additionally, the gene organization of contigs containing the fused $m u r B / C$ open reading frame (ORF) was further analyzed with EasyFig version 2.1 (Sullivan et al., 2011). Additional MurB and MurC proteins were also mined from the UniProt (http://www.uniprot.org/) (The UniProt Consortium) to be included for phylogenetic analysis. Briefly, the proteins were aligned and trimmed using mafft-linsi and trimal (-gappyout setting) (Capella-Gutiérrez et al., 2009; Katoh and Standley, 2013), and phylogenetic inference was performed using IQ-TREE version 1.3.10 (Nguyen et al., 2014) and visualized using FigTree version 1.42 (http://tree.bio.ed.ac.uk/software/figtree/).

\section{PCR Amplification and Cloning of the $V$. spinosum murB/C Open Reading Frame (ORF)}

The ORF annotated by the locus tag (VspiD_010100018130) UDP- $N$-acetylenolpyruvoylglucosamine reductase /UDP- $N$ acetylmuramate:L-alanine ligase was amplified by PCR using the primers $m u r B / C_{V s}$-forward (5'-CACCATGAATCACGCC GTCGTCAGTTTGTTGAAG-3 ${ }^{\prime}$ ) and $m u r B / C_{V s}$-reverse $\left(5^{\prime}\right.$ GTCGACCTATAGCGGAAGCGGTTCCTCTTCGCCAAT-3').

The underlined sequence represents the restriction enzyme site used to facilitate sub-cloning of the ORF while the bold sequences represent initiation and termination codons. The PCR reaction contained $12 \mathrm{pmol}$ of forward and reverse primers, $1 \mathrm{mM} \mathrm{MgSO} 4,0.5 \mathrm{mM}$ of each of the four deoxynucleotide triphosphates, $0.5 \mathrm{ng}$ of genomic DNA and 1 unit of Platinum Pfx DNA polymerase (Invitrogen Corporation, Carlsbad, CA, USA). PCR conditions were: 1 cycle at $94^{\circ} \mathrm{C}$ for $2 \mathrm{~min}$, followed by 30 cycles of $94^{\circ} \mathrm{C}$ for $15 \mathrm{~s}, 60^{\circ} \mathrm{C}$ for $30 \mathrm{~s}$, and $72^{\circ} \mathrm{C}$ for 3 min. The murB/C PCR fragment was ligated into the plasmid pET100D/topo (Invitrogen Corporation, Carlsbad, CA, USA)
TABLE 1 | Plasmids and strains used in this study.

\begin{tabular}{|c|c|}
\hline Plasmids and strains & Sources/References \\
\hline \multicolumn{2}{|l|}{ PLASMIDS } \\
\hline pET100D/topo & Invitrogen, USA \\
\hline pBAD33 & Guzman et al., 1995 \\
\hline pET100D::murB/C $V_{S s}$ & This study \\
\hline pBAD33::murB/C $C_{V s}$ & This study \\
\hline pTrcHis60 & Pompeo et al., 1998 \\
\hline pTrcHis60::murB $v_{s^{-1}}$ & This study \\
\hline pTrcHis60::murB $V_{V_{s}}-2$ & This study \\
\hline pTrcHis60::murC $V_{s}-1$ & This study \\
\hline pTrcHis60::murC $V_{s}-2$ & This study \\
\hline pTrcHis60::murC $E_{E C}$ & Liger et al., 1995 \\
\hline \multicolumn{2}{|l|}{ STRAINS } \\
\hline Verrucomicrobium spinosum DSM $4136^{T}$ & Schlesner, 1987 \\
\hline 5-alpha competent cells & New England Biolabs, USA \\
\hline Rosetta codon plus RIPL & Agilent, Technologies, USA \\
\hline Rosetta (DE3) pLysS & Novagen, USA \\
\hline E. coli murB (ST5) CGSC Strain \# 6442 & $\begin{array}{l}\text { Matsuzawa et al., 1969; Miyakawa } \\
\text { et al., } 1972\end{array}$ \\
\hline E. coli murC (ST222) CGSC Strain \# 5988 & Miyakawa et al., 1972 \\
\hline E. coli murC (H1119) & Wijsman, 1972 \\
\hline E. coli murB (pBAD33) & This study \\
\hline E. coli murC (pBAD33) & This study \\
\hline E. coli murB (pBAD33::murB/ $C_{V s}$ ) & This study \\
\hline E. coli murC (pBAD33::murB/C $V_{V s}$ ) & This study \\
\hline
\end{tabular}

to produce the plasmid pET100D::murB/ $C_{V s}$. The recombinant protein encoded by this plasmid carries an N-terminal MRGSHHHHHHGMASMTGGQQMGRDLYDDDDKDHPFT additional sequence containing a hexa-histidine tag (bold) derived from the pET100D plasmid. To confirm the fidelity of the PCR reaction, the ORF was sequenced from pET100D using the T7 promoter primer, 5'-TAATACGACTCACTATAGGG-3' and the T7 reverse primer, $5^{\prime}$-TAGTTATTGCTCAGCGGTGG$3^{\prime}$. The cloned murB/C ORF was $100 \%$ identical to the sequence deposited in the Integrated Microbial Genomes public database (http://img.jgi.doe.gov/cgi-bin/w/main.cgi).

\section{Cloning of murC and murB Domains}

The $m u r C$ and murB domains of the $\mathrm{MurB} / \mathrm{C}_{V s}$ fusion protein were also cloned separately in expression vectors, as follows. The murC domain sequence (two different end points were chosen) was amplified by PCR by using $\operatorname{murC}_{V s}$-forward (5'-GCGCTCATGAATCACGCCGTCGTCAGTTTGTTGA $\left.\mathrm{AG}-3^{\prime}\right)$ as the forward primer and either $\operatorname{murC}_{V s}$-reverse-1 (5'-GCGCAGATCTGCCTTCGCGATTGAGCACCGTAGT GAG-3') or murC $_{V s}$-reverse-2 (5'-GCGCAGATCTGACCGT GCCACCGCCTTCGCGATTGAG-3') as the reverse primer, designed to end the MurC domain at the Gly477 and Val481 residues, respectively. The underlined sequences correspond to introduced BspHI and BglII restriction sites and the murC gene initiation codon is indicated in bold. The two PCR 
products were digested by $B s p H I$ and $B g l \mathrm{II}$ and inserted between the compatible NcoI and BglII sites of the expression vector p TrcHis60 that allows expression of proteins with a C-terminal hexa-histidine tag under the control of the IPTG-inducible trc promoter (Pompeo et al., 1998). The two plasmids thus generated, pTrcHis60::murC $C_{V s}-1$ and p TrcHis60::murC $C_{v s}-2$, directed expression of Met1-Gly477 and Met1-Val481 fragments from the MurB/ $\mathrm{C}_{V s}$ fusion protein (770 residues in total), respectively, fused to a $\mathrm{C}$-terminal tag extension consisting in Arg-Ser-His 6 .

Similarly, the $\operatorname{murB}$ domain sequence (two different starting points were chosen) was amplified by using either $m u r B_{V s^{-}}$ forward-1 (5'-GAAGCCATGGGCACGGTCAAGCTCTATGA GCCGATG-3') or murB $_{V s}$-forward-2 (5'-GCGCTCATGAAGC TCTATGAGCCGATGGCCAACCAC- $3^{\prime}$ ) as the forward primer and $m u r B_{V s}$-reverse $\left(5^{\prime}\right.$-GCGCAGATCTTAGCGGAAGCGG TTCCTCTTCGCCAATG-3') as the reverse primer. NcoI, BspHI and $B g l \mathrm{II}$ restriction sites introduced in these sequences are underlined and the murB gene initiation codons are indicated in bold. The two PCR products were digested by NcoI or $B s p H I$ and BglII and inserted between the compatible NcoI and BglII sites of the vector pTrcHis60. The two plasmids thus generated, pTrcHis60::murB $B_{V s}-1$ and $\mathrm{p} \operatorname{Tr} c \mathrm{His} 60:: m u r B_{V s}-2$, directed expression of the Gly479-Leu770 and Lys482-Leu770 fragments (preceded by a Met residue) from the MurB/C $\mathrm{C}_{V}$ fusion protein, respectively, here too with a C-terminal tag consisting in Arg-Ser-His 6 .

\section{Expression and Purification of Recombinant MurB/ $\mathrm{C}_{V_{s}}$}

The E. coli Rosetta (DE3) pLysS strain (Novagen) was transformed with the plasmid pET100D::murB/ $C_{V s}$ and grown at $37^{\circ} \mathrm{C}$ in $2 \mathrm{YT}$ medium containing $50 \mu \mathrm{g} \cdot \mathrm{mL}^{-1}$ ampicillin and $25 \mu \mathrm{g} \cdot \mathrm{mL}^{-1}$ chloramphenicol. An overnight pre-culture of the resulting strain was used to inoculate $2 \mathrm{YT}$ medium (2-liter cultures). The culture was incubated with shaking at $37^{\circ} \mathrm{C}$. When the optical density reached 0.9 , the temperature of the culture was decreased to $20^{\circ} \mathrm{C}$ and IPTG was added at a $1 \mathrm{mM}$ final concentration. Growth was continued for $18 \mathrm{~h}$ at $20^{\circ} \mathrm{C}$. Cells were harvested at $4^{\circ} \mathrm{C}$ and the pellet was washed with cold 20

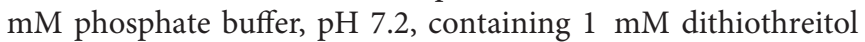
(buffer A). Bacteria were resuspended in buffer A $(12 \mathrm{~mL})$ and disrupted by sonication in the cold using a Bioblock Vibracell 72412 sonicator. The resulting suspension was centrifuged at $4^{\circ} \mathrm{C}$ for $30 \mathrm{~min}$ at 200,000 $\times g$ with a Beckman TL100 apparatus, and the pellet was discarded. The supernatant was kept at $-20^{\circ} \mathrm{C}$.

The His 6 -tagged protein was purified on $\mathrm{Ni}^{2+}$. nitrilotriacetate $\left(\mathrm{Ni}^{2+}-\mathrm{NTA}\right)$-agarose following the manufacturer's recommendations (Qiagen). All procedures were performed at $4^{\circ} \mathrm{C}$. The supernatant was mixed for $1 \mathrm{~h}$ with the polymer previously washed with buffer A containing $0.3 \mathrm{M} \mathrm{KCl}$ and $10 \mathrm{mM}$ imidazole. Washing and elution steps were performed with a discontinuous gradient of imidazole (20-300 mM) in buffer A containing 0.3 M KCl. Protein contents were analyzed by sodium dodecyl sulfate-polyacrylamide gel electrophoresis (SDS-PAGE) and relevant fractions were pooled and dialyzed against 100 volumes of buffer A. At this step, precipitation of a significant part of the protein was observed. The non-precipitated protein was concentrated on an Amicon Ultra 50,000 molecular mass cutoff filter. Glycerol (10\% final concentration) was added for storage at $-20^{\circ} \mathrm{C}$. Protein concentrations were determined by quantitative amino acid analysis with a Hitachi L8800 analyzer (ScienceTec) after hydrolysis of samples at $105^{\circ} \mathrm{C}$ for $24 \mathrm{~h}$ in $6 \mathrm{M} \mathrm{HCl}$ containing $0.05 \% 2$-mercaptoethanol. No attempts were made to remove the additional sequence containing the hexa-histidine tag after protein purification.

\section{Construction of the Plasmid to Facilitate Functional Complementation}

The plasmid used for functional complementation of the E. coli murB and murC mutants was produced by sub-cloning the $\mathrm{XbaI}$ and SalI fragment from the pET100D::murB/ $C_{V s}$ plasmid into pBAD33 to produce the plasmid pBAD33::murB/ $C_{V s}$, which is under control of the arabinose inducible promoter (Guzman et al., 1995). The protein produced from the pBAD33 construct is identical to the protein produced from the pET100D construct. Note that there is an XbaI site 20 base pairs upstream of the ribosome binding site of the $\mathrm{pET} 100 \mathrm{D}$ vector that was used to facilitate sub-cloning from pET100D into pBAD33.

\section{Functional Complementation of the E. coli murB and murC Thermosensitive Mutants}

The E. coli murB mutant (ST5-strain \#6442) [thr-1, araC14, leuB6 (Am), secA216, fhuA61, lacY1, galT23, $\lambda^{-}$trp-84, his215, thyA710, rpsL263 (strR), xylA5, mtl-1, murB1-(ts), thi1] and murC mutant (ST222-strain \#5988) [thr-1, araC14, leuB6 (Am), murC3(ts), secA216, fhuA61, lacY1, galT23, $\lambda^{-}$ trp-84, his-215, thyA710, rpsL263 (strR), xylA5, mtl-1, thi1] were both obtained from the Coli Genetic Stock Center (http://cgsc.biology.yale.edu/). These mutants were transformed with the $\mathrm{pBAD} 33$ vector or the $\mathrm{pBAD} 33::$ murB $/ C_{V s}$ plasmid and transformants were selected on LB agar medium supplemented with $50 \mu \mathrm{g} \cdot \mathrm{mL}^{-1}$ thymine, $34 \mu \mathrm{g} . \mathrm{mL}^{-1}$ chloramphenicol, and $0.2 \%(\mathrm{w} / \mathrm{v})$ arabinose at $30^{\circ} \mathrm{C}$. Colonies were then replica-plated onto LB agar medium plus $0.2 \%(\mathrm{w} / \mathrm{v})$ arabinose and $10 \mu \mathrm{g} \cdot \mathrm{mL}^{-1}$ thymine. Liquid cultures were also performed in LB medium supplemented with arabinose and thymine. In both cases, the growth phenotype was assessed at 30 and $42^{\circ} \mathrm{C}$ for up to $24 \mathrm{~h}$.

As described above, the individual murC and murB domains from the $m u r B / C_{V s}$ fusion gene were also cloned separately in the p TrcHis60 vector that allows high-level gene expression under control of the strong IPTG-dependent $t r c$ promoter. The resulting plasmids $\mathrm{p} \operatorname{TrcHis60::murB_{Vs}}$ and $\mathrm{p} \operatorname{Tr} \mathrm{H}$ His60::murC $\mathrm{V}_{V}$ were then tested for functional complementation, using the $E$. coli murB mutant ST5 and the murC mutant strain H1119 (Wijsman, 1972), respectively. Transformants were selected on LB agar medium supplemented with $100 \mu \mathrm{g} \cdot \mathrm{mL}^{-1}$ ampicillin and $50 \mu \mathrm{g} \cdot \mathrm{mL}^{-1}$ thymine at $30^{\circ} \mathrm{C}$ and were subsequently replicated on similar plates incubated at $30^{\circ} \mathrm{C}$ or $42^{\circ} \mathrm{C}$, in the presence or absence of $0.5 \mathrm{mM}$ IPTG. Growth was observed after $24 \mathrm{~h}$ of incubation. 


\section{Determination of the Kinetic Constants of the MurC Activity}

The standard MurC activity assay (Liger et al., 1995) measured the formation of UDP-MurNAc-L-Ala in a mixture (final volume, $40 \mu \mathrm{L}$ ) containing $100 \mathrm{mM}$ Tris- $\mathrm{HCl}, \mathrm{pH} 9.0,10 \mathrm{mM}$ $\mathrm{MgCl}_{2}, 3 \mathrm{mM}$ ATP, $10 \mathrm{mM}$ ammonium sulfate, $0.5 \mathrm{mg} \cdot \mathrm{mL}^{-1}$ bovine serum albumin (BSA), $0.9 \mathrm{mM}$ UDP-MurNAc, $0.3 \mathrm{mM}$ $\mathrm{L}-\left[{ }^{14} \mathrm{C}\right] \mathrm{Ala}(400 \mathrm{~Bq})$, and enzyme $(20 \mu \mathrm{L}$ of an appropriate dilution in buffer A). For the determination of the $K_{m}$ values for UDP-MurNAc, UDP- $\left[{ }^{14} \mathrm{C}\right]$ MurNAc was used as the radiolabelled substrate.

In all cases, the mixtures were incubated for $30 \mathrm{~min}$ at $37^{\circ} \mathrm{C}$ and the reactions were stopped by the addition of glacial acetic acid $(10 \mu \mathrm{L})$ followed by lyophilization. Radioactive substrate and product were then separated by HPLC on a Nucleosil $100 \mathrm{C}_{18}$ $5 \mu \mathrm{m}$ column $(150 \times 4.6 \mathrm{~mm}$; Alltech France $)$ using $50 \mathrm{mM}$

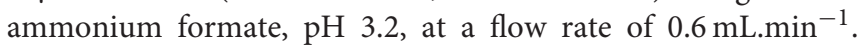
Radioactivity was detected with a flow detector (model LB506C1, Berthold) using the Quicksafe Flow 2 scintillator (Zinsser Analytic) at $0.6 \mathrm{~mL} \cdot \mathrm{min}^{-1}$. Quantification was performed with the Radiostar software (Berthold).

For the determination of the kinetic constants, the same assay was used with various concentrations of one substrate and fixed concentrations of the others. In all cases, the enzyme concentration was chosen so that substrate consumption was $<20 \%$, the linearity being ensured within this interval even at the lowest substrate concentration. Data were fitted to the equation $v=V_{\max } S /\left(K_{m}+S\right)$ by the Levenberg-Marquardt method (Press et al., 1986), where $v$ is the initial velocity and $S$ is the substrate concentration, and values \pm standard deviation at $95 \%$ of confidence were calculated. The MDFitt software developed by M. Desmadril (I2BC, Orsay, France) was used for this purpose.

\section{In vitro Spectrophotometric Assay of the MurB Activity}

The MurB spectrophotometic assay was performed as described previously (Benson et al., 1993). The reaction mixture contained, in a final volume of $100 \mu \mathrm{L}, 50 \mathrm{mM}$ Tris- $\mathrm{HCl}, \mathrm{pH}$ 8.0, $20 \mathrm{mM} \mathrm{KCl}$, $0.5 \mathrm{mM}$ dithiothreitol, $0.1 \mathrm{mM}$ UDP-GlcNAc-EP, and $0.15 \mathrm{mM}$ NADPH. The mixture was placed in a $1-\mathrm{cm}$ path length cell and the reaction was started by the addition of the enzyme. The decrease in NADPH absorbance at $340 \mathrm{~nm}$ was monitored with a Jasco V-630 spectrophotometer.

\section{In vitro Coupled Assay of the MurA/MurB Activities}

The reaction mixture contained, in a final volume of $40 \mu \mathrm{L}$, $50 \mathrm{mM}$ Tris- $\mathrm{HCl}, \mathrm{pH} 7.6,25 \mathrm{mM} \mathrm{KCl}, 0.1 \mathrm{mM}$ NADPH, 55 $\mu \mathrm{M}$ UDP- $\left[{ }^{14} \mathrm{C}\right] \mathrm{GlcNAc}(500 \mathrm{~Bq}), 75 \mu \mathrm{M}$ phosphoenolpyruvate, E. coli MurA (1 $\mu \mathrm{g})$, and enzyme. In some experiments, $5 \mathrm{mM}$ ATP, $10 \mathrm{mM} \mathrm{MgCl}_{2}$, and $0.15 \mathrm{mM} \mathrm{L}$-Ala were included. After 30 min at $37^{\circ} \mathrm{C}$, the reaction was stopped by the addition of glacial acetic acid $(8 \mu \mathrm{L})$ followed by lyophilization. The radioactive substrate and product were separated on a Nucleosil $100 \mathrm{C}_{18}$ $5 \mu \mathrm{m}$ column $(150 \times 4.6 \mathrm{~mm}$; Alltech France $)$ using $50 \mathrm{mM}$ ammonium formate, $\mathrm{pH} 3.2$, at a flow rate of $0.6 \mathrm{~mL} \cdot \mathrm{min}^{-1}$. Detection and quantification of the radioactivity were performed as described above. The retention times for UDP-GlcNAc, UDPGlcNAc-EP, UDP-MurNAc, and UDP-MurNAc-L-Ala were 6, 10, 12 , and $20 \mathrm{~min}$, respectively.

\section{MurB/ $\mathrm{C}_{V s}$ Cleavage Assay}

For the cleavage assay, V. spinosum was grown in liquid medium R2A medium supplemented with $5 \%(\mathrm{w} / \mathrm{v})$ artificial sea water at $26^{\circ} \mathrm{C}$ for 5 days. Following centrifugation, the cells were lysed by sonication in the following buffer systems $50 \mathrm{mM}$ Tris- $\mathrm{HCl}, \mathrm{pH}$ 7.6, $50 \mathrm{mM}$ Tris-HCl, $\mathrm{pH}$ 8.5, and $50 \mathrm{mM}$ HEPES-KOH, pH 7.6. The purified recombinant enzyme $(7.5 \mu \mathrm{g})$ was incubated with $15 \mu \mathrm{g}$ of $V$. spinosum extract at $30^{\circ} \mathrm{C}$. The proteins were resolved on a $10 \%(\mathrm{w} / \mathrm{v})$ acrylamide gel and stained with Coomassie blue for visualization. Protein concentration was measured using the Bradford assay with BSA as the standard (Bradford, 1976).

\section{RESULTS}

\section{Identification of the MurB/C Fusion Enzyme from V. spinosum}

The complete set of genes in $V$. spinosum required for the de novo synthesis of PG was initially identified from a comparative analysis of the $V$. spinosum proteome using the known PG biosynthesis proteins as queries (Nachar et al., 2012). The search revealed an anomaly when it was realized that both the MurB and MurC proteins were encoded by a single locus tag VspiD_010100018130 (Table 2).

\section{Domain Mapping of the MurB/C Fusion Enzyme from $V$. spinosum}

The length of the MurB and MurC E. coli proteins are 342 and 491 residues, respectively, and the lengths of the MurB/C fusion enzyme protein is 770 residues. As such, we were interested to assess if the fusion enzyme had the domains that are indicative of typical MurB and MurC enzymes. Domains were identified using the NCBI's CDD and the protein families database (Pfam) (Finn et al., 2014; Marchler-Bauer et al., 2015). The CDD and Pfam analyses resulted in the identification of the following domains: (1) the Mur ligase catalytic domain (Pfam01225), (2) the Mur ligase middle domain (Pfam08245), (3) the Mur ligase family amino acid-binding domain (Pfam02875), (4) the FAD-binding domain (Pfam01565), and (5) the UDP$\mathrm{N}$-acetylenolpyruvoylglucosamine reductase C-terminal domain (Pfam02873). This analysis also demonstrated that the residues responsible for the MurC activity were located toward the $\mathrm{N}$ terminal end of the fusion enzyme, while those for the MurB activity are located toward the C-terminal end. MurC and MurB are separated by a linker region of $\sim 100$ residues as depicted in the schematic. For comparison, the figure also depicts the domain structures of the E. coli MurB and MurC enzymes (Figure 3).

\section{The $m u r B / C_{V s}$ Gene is able to Functionally Complement the E. coli murB and murC Mutants}

The E. coli strains ST5 and ST222 obtained from the Coli Genetic Stock Center harbor mutations in the murB and murC 
TABLE 2 | List of PG biosynthesis genes from V. spinosum.

\begin{tabular}{|c|c|c|c|}
\hline Protein symbol & Gene product name & EC \# & Locus Tag \\
\hline MurA & UDP-N-acetylglucosamine 1-carboxyvinyltransferase & 2.5.1.7 & VspiD_010100011745 \\
\hline MurB & UDP-N-acetylenolpyruvoylglucosamine reductase & 1.3.1.98 & VspiD_010100018130 \\
\hline MurC & UDP-N-acetylmuramate:L-alanine ligase & 6.3.2.8 & VspiD_010100018130 \\
\hline Murl & Glutamate racemase & 5.1 .1 .3 & VspiD_010100008415 \\
\hline MurD & UDP-N-acetylmuramoyl-L-alanine:D-glutamate ligase & 6.3 .2 .9 & VspiD_010100019115 \\
\hline MurE & UDP-N-acetylmuramoyl-L-alanyl-D-glutamate:2,6-diaminopimelate ligase & 6.3 .2 .13 & VspiD_010100019130 \\
\hline MurF & UDP-N-acetylmuramoyl-tripeptide:D-alanyl-D-alanine ligase & 6.3.2.10 & VspiD_010100019125 \\
\hline AlaR & Alanine racemase & 5.1 .1 .1 & VspiD_010100000100 \\
\hline Ddl & D-alanine:D-alanine ligase & 6.3.2.4 & VspiD_010100018175 \\
\hline MraY & Phospho- $N$-acetylmuramoyl-pentapeptide transferase & 2.7.8.13 & VspiD_010100019120 \\
\hline MurG & Undecaprenyl-diphospho- $N$-acetylmuramoyl-pentapeptide $\beta-N$-acetylglucosaminyl transferase & 2.4.1.227 & VspiD_010100019100 \\
\hline UppP & Undecaprenyl-diphosphate phosphatase & 3.6.1.27 & VspiD_010100026230 \\
\hline PBP & D-alanyl-D-alanine carboxypeptidase-class C & 3.4.16.4 & VspiD_010100024635 \\
\hline PBP & Multimodular transpeptidase-transglycosylase-class A & 2.4.1.129 & VspiD_010100022270 \\
\hline PBP & Penicillin-binding protein 1C- class A & 2.4.1.129 & VspiD_010100006740 \\
\hline PBP & Penicillin-binding protein 2-class A & 2.4.1.129 & VspiD_010100020475 \\
\hline PBP & Peptidoglycan transpeptidase-class B & 2.4.1.129 & VspiD_010100007940 \\
\hline PBP & Peptidoglycan transpeptidase-class B & 2.4.1.129 & VspiD_010100017450 \\
\hline PBP & Peptidoglycan synthetase Ftsl-class B & 2.4.1.129 & VspiD_010100019135 \\
\hline PBP & Cell elongation specific D,D-transpeptidase- class B & 2.4.1.129 & VspiD_010100018680 \\
\hline
\end{tabular}

The information for MurB and MurC is in bold. EC \# denotes enzyme classification number.

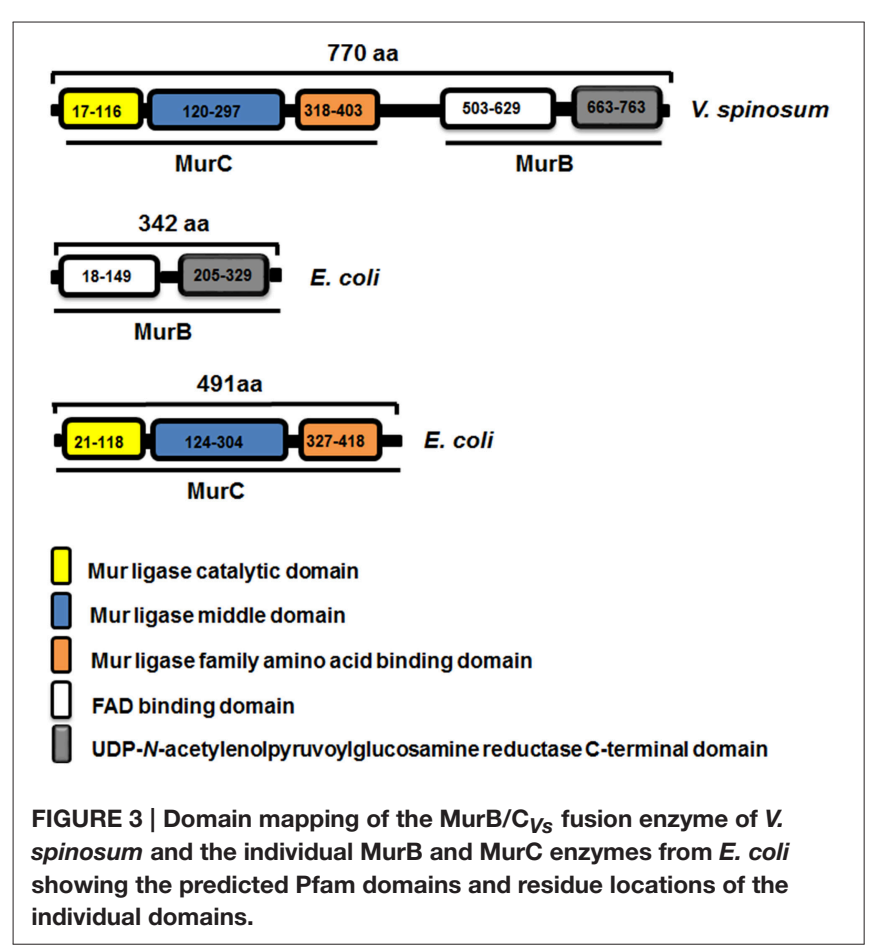

genes, respectively. These mutations result in a temperaturesensitive growth phenotype where the mutants are able to grow at the permissive temperature of $30^{\circ} \mathrm{C}$, but not at the non-permissive temperature of $42^{\circ} \mathrm{C}$ (Matsuzawa et al., 1969;
Miyakawa et al., 1972). To answer the question of whether the fusion gene is able to complement the murB and murC E. coli mutants, the mutant strains were transformed with an empty vector (pBAD33) or with a vector containing the murB/C gene (pBAD33::murB/ $C_{V s}$ ). Using replica-plating, the results from this analysis demonstrate that at the permissive temperature of $30^{\circ} \mathrm{C}$, the mutant strains harboring the vector control (pBAD33) and the vector containing the recombinant gene (pBAD33::murB/ $C_{V s}$ ) were both able to grow. However, when exposed to the non-permissive temperature of $42^{\circ} \mathrm{C}$, only the strains expressing the $m u r B / C$ recombinant gene were able to grow (Figure 4A). This result was corroborated by assessing bacterial growth in liquid medium over a period of $24 \mathrm{~h}$. At $30^{\circ} \mathrm{C}$ the mutants harboring the vector-only and the $\mathrm{murB} / \mathrm{C}-$ expressing vector grew as expected. The growth phenotype at the non-permissive temperature of $42^{\circ} \mathrm{C}$ demonstrated that only the mutant strains expressing the $m u r B / C$ gene were able to grow when compared to the vector-only controls (Figure 4B). The lack of growth based on the optical density of the vector-only controls at $42^{\circ} \mathrm{C}$ can be attributed to rapid lysis of the cells due to the lack of proper peptidoglycan synthesis (Figure 4B). The assessment of crude soluble protein extracts from the complementation experiment using SDS-PAGE analysis confirmed the production of the recombinant MurB/C fusion enzyme $(\sim 87.3 \mathrm{kDa})$ in the mutant backgrounds grown at $42^{\circ} \mathrm{C}$ that was not present in the extracts from the mutant harboring the vector-only control when both were under inducing conditions using arabinose (Figure 4C). Together, these analyses demonstrated that the recombinant MurB/C fusion enzyme from $V$. spinosum was endowed with the reductase (MurB) and ligase (MurC) activities, 
and that the amount produced was sufficient to sustain the growth of the E. coli mutants.

Attempts to clone and assay the in vivo activity of the individual MurB and MurC domains of the $\mathrm{MurB} / \mathrm{C}_{V s}$ fusion protein were then made. Protein dissection was performed on the basis of the mapping experiments described above, i.e., alignment of the $V$. spinosum protein sequence with that of MurB and MurC ortholog proteins from E. coli. These two domains were cloned in the $\mathrm{p} \operatorname{Tr} \mathrm{His} 60$ vector, in each case in two versions: with the MurC domain starting at the Met1 residue and terminating either at the Gly477 or the Val481 residue, and the MurB domain starting either at the Gly479 or the Lys482 residue (preceded by a Met residue) and terminating at the last residue (Leu770) of the fusion protein. The two p TrcHis60:: ur $_{V s}$ constructs thus generated complemented the thermosensitive murC mutant strain $\mathrm{H} 1119$, indicating that the shortest version ending at Gly477 clearly exhibited MurC activity. IPTG was not required for complementation, indicating that basal expression of the $m u r C_{V s}$ domain from the pTrcHis60 vector was sufficient to sustain cell growth and viability of the murC mutant at the non-permissive temperature of $42^{\circ} \mathrm{C}$ (Supplemental Figure 1). However, the two other $\mathrm{p} \operatorname{Tr} \mathrm{His} 60:: \operatorname{mur} B_{V s}$ constructs failed to complement the growth defect of the murB mutant strain ST5 and induction of gene expression with $0.5 \mathrm{mM}$ IPTG yielded the same result. The latter finding could be interpreted in several ways: inappropriate design of the $\operatorname{murB}$ domain initiation codon, physical instability of these truncated forms of the fusion protein, or inability of the MurB domain to function independently (absolute requirement for the presence of the MurC domain). Our data show that this is not the case for the MurC domain whose activity did not depend on the presence of the MurB domain.

\section{Properties and Kinetic Parameters of MurC Activity from MurB/ $\mathrm{C}_{V_{s}}$}

The in vitro L-alanine-ligase activity of the $\mathrm{MurB} / \mathrm{C}_{V s}$ fusion enzyme was revealed using a radioactive assay, which was also used to determine the properties and kinetic parameters (Table 3). The optimal $\mathrm{pH}$ and temperature for $\mathrm{MurC}_{V s}$ were found to be 9.0 and $44-46^{\circ} \mathrm{C}$, respectively. As it is the case for the other Mur ligases (Barreteau et al., 2008), magnesium ions were essential for the activity: the optimal concentration was $10 \mathrm{mM}$. It was shown that the addition of $10 \mathrm{mM}$ ammonium sulfate and $0.5 \mathrm{mg} \cdot \mathrm{mL}^{-1}$ BSA increased the activity by 35 and

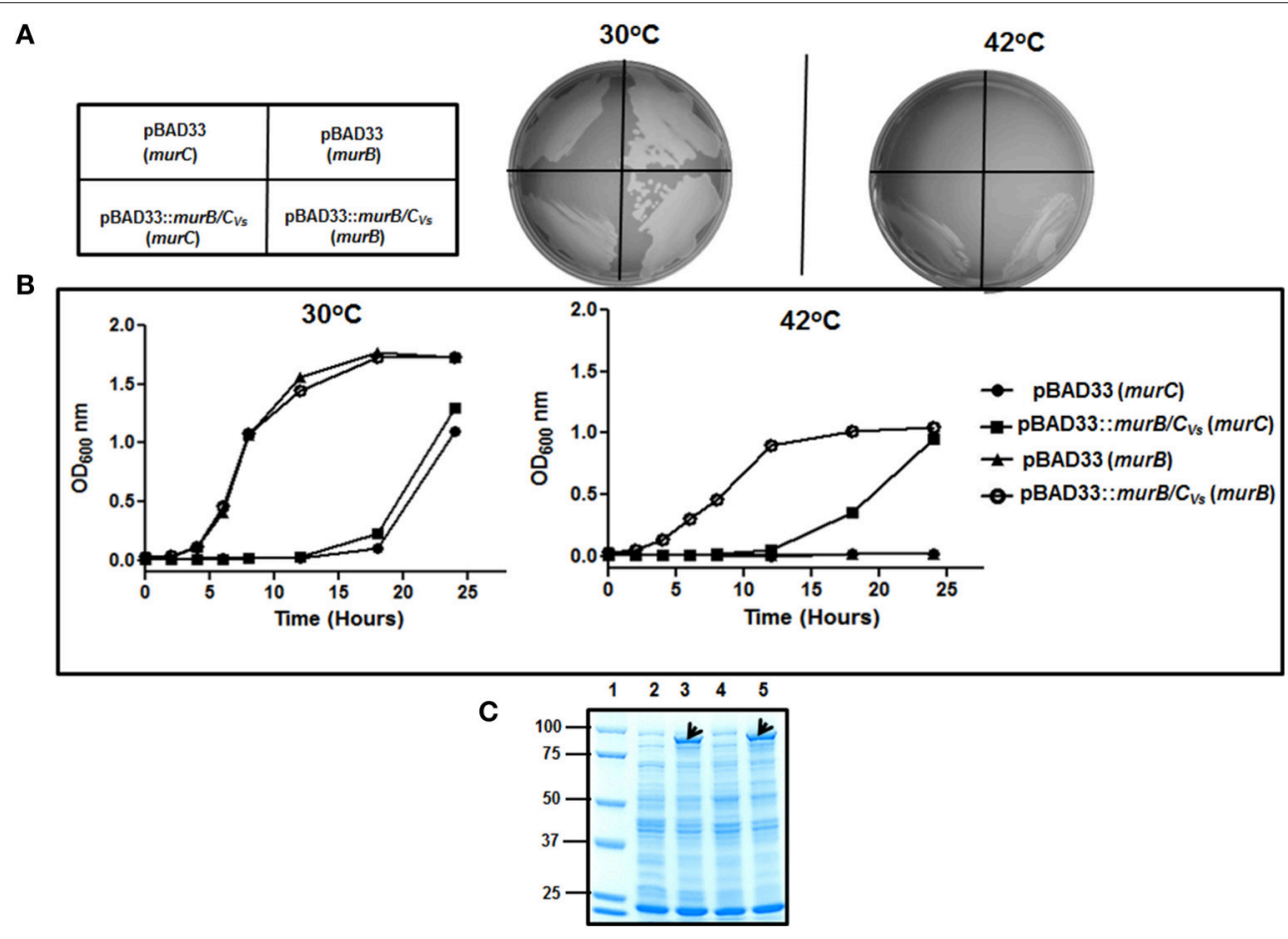

FIGURE 4 | Functional complementation analysis of the $\mathbf{E}$. coli murB and murC mutants. (A) Replica-plating experiment of the murC and murB mutants transformed with pBAD33 and pBAD33::murB/ $\mathrm{C}_{V_{s}}$ grown at 30 and $42^{\circ} \mathrm{C}$. (B) Analysis of the complementation experiment at 30 and $42^{\circ} \mathrm{C}$ in liquid culture assessing the growth phenotype by measurement of the optical density (OD) at $600 \mathrm{~nm}$ for a $24 \mathrm{~h}$ period. The growth experiments were done four times giving the similar growth profiles. The graphs in (B) represent one of those growth curves. (C) SDS-PAGE analysis of proteins from the complementation experiment to assess the expression of MurB/C in the mutant backgrounds. Lane (1), protein ladder (kDa). Lane (2), $10 \mu \mathrm{g}$ of protein extract from the E. coli murC mutant harboring pBAD33 grown at $30^{\circ} \mathrm{C}$. Lane (3), $10 \mu \mathrm{g}$ of protein extract from the $E$. coli murC mutant harboring pBAD33::murB/ $V_{V s}$ grown at $42^{\circ} \mathrm{C}$. Lane (4), $10 \mu \mathrm{g}$ of protein extract from the $E$. coli murB mutant harboring pBAD33 grown at $30^{\circ} \mathrm{C}$. Lane (5), $10 \mu \mathrm{g}$ of protein extract from the $E$. coli murB mutant harboring $\mathrm{pBAD} 33:: m u r B / \mathrm{C}_{V s} \mathrm{grown}$ at $42^{\circ} \mathrm{C}$. Crude extracts were obtained via sonication after $24 \mathrm{~h}$ from the samples grown at $30^{\circ} \mathrm{C}$ and $42^{\circ} \mathrm{C}$. The black arrows show expression of the MurB/C recombinant enzyme. The proteins were resolved on a $10 \%(\mathrm{w} / \mathrm{v})$ acrylamide gel and stained with Coomassie blue for visualization. 
TABLE 3 | Properties and apparent kinetic parameters of $V$. spinosum MurC in comparison with its orthologs from E. coli and C. trachomatis.

\begin{tabular}{|c|c|c|c|}
\hline Kinetic parameter & $\operatorname{MurC}_{V s}{ }^{a}$ & MurC $_{E c}{ }^{b}$ & MurC $_{C t}{ }^{c}$ \\
\hline Optimal pH & 9.0 & 8.6 & $8.0-8.5$ \\
\hline Optimal $\mathrm{Mg}^{2+}$ concentration (mM) & 10 & $10-20$ & 20 \\
\hline Optimal temperature $\left({ }^{\circ} \mathrm{C}\right)$ & $44-46$ & 45 & $n d^{d}$ \\
\hline$K_{\mathrm{m}}^{\mathrm{ATP}}(\mu \mathrm{M})$ & $470 \pm 160$ & 450 & 162 \\
\hline$K_{\mathrm{m}}^{\mathrm{UDP}-\mathrm{MurNAc}}(\mu \mathrm{M})$ & $90 \pm 25$ & 100 & 196 \\
\hline$K_{\mathrm{m}}^{\mathrm{L}-\mathrm{Ala}}(\mu \mathrm{M})$ & $25 \pm 10$ & 20 & 124 \\
\hline$V_{\max }\left(\mathrm{nmol} \cdot \min ^{-1} \cdot \mathrm{mg}^{-1}\right)$ & $5500 \pm 50$ & 17300 & 73.8 \\
\hline
\end{tabular}

a The apparent kinetic parameters were determined as described in Section Materials and Methods. The concentrations of the fixed substrates were $5 \mathrm{mM}$ for ATP, $1 \mathrm{mM}$ for UDPMurNAc, and $0.2 \mathrm{mM}$ for L-Ala. The concentration ranges for the varied substrates were 0.2-5 mM for ATP, 25-500 $\mu \mathrm{M}$ for UDP-MurNAc, and 10-400 $\mu \mathrm{M}$ for L-Ala.

${ }^{b}$ From (Liger et al., 1995).

${ }^{c}$ From (Hesse et al., 2003).

${ }^{d}$ nd, not determined.

TABLE 4 | Specificity of MurC $V_{s}$ for the amino acid substrate.

\begin{tabular}{lc}
\hline Substrate & Enzymatic activity (nmol.min $\left.\mathbf{~}^{\mathbf{1}} \cdot \mathbf{m g}^{\mathbf{- 1}}\right)^{\mathbf{a}}$ \\
\hline L-Ala & $4900 \pm 250$ \\
L-Ser & $3200 \pm 130$ \\
Gly & $3570 \pm 220$ \\
\hline
\end{tabular}

a Determined as described in Section Materials and Methods with fixed concentrations of ATP (5 mM), UDP-MurNAc (1.5 mM), and amino acid (1.5 mM).

$55 \%$, respectively. With L-alanine as the amino acid substrate, the apparent $k_{\text {cat }}$ of the enzyme was $480 \mathrm{~min}^{-1}$ ( $V_{\max }$, ca. 5500 nmol. $\mathrm{min}^{-1} \cdot \mathrm{mg}^{-1}$ ). Amino acids Gly and L-Ser, which are found at position 1 of the peptide stem in some bacteria (Schleifer and Kandler, 1972; Vollmer et al., 2008), were also tested as substrates (Table 4). L-Ala was the best substrate, which is in agreement with the amino acid composition of $V$. spinosum peptidoglycan (McGroty et al., 2013). However, the difference with the two others was not as important as for the E. coli MurC ortholog (Liger et al., 1995).

\section{Attempts to Demonstrate the In vitro MurB Activity from MurB/C $v_{v s}$}

Several attempts were made to measure the in vitro reductase activity of MurB/ $\mathrm{C}_{V s}$ with two assays: a spectrophotometric assay using commercial UDP-GlcNAc-EP and NADPH, and a coupled MurA/MurB assay using UDP- $\left[{ }^{14} \mathrm{C}\right] \mathrm{GlcNAc}$ and E. coli MurA. However, neither decrease of absorbance at $340 \mathrm{~nm}$ nor appearance of labeled UDP-MurNAc occurred, even at high protein concentrations. It was checked that the expected reaction took place in both assays when $\mathrm{MurB} / \mathrm{C}_{V s}$ was replaced by $E$. coli MurB (data not shown). In order to ascertain that the absence of reaction in the coupled assay was not due to strong inhibition by the MurB product, L-alanine, ATP, and $\mathrm{Mg}^{2+}$ were added so that the MurC $_{V s}$ activity might displace the reaction toward the right. A new radioactive compound appeared, but its retention time (25 $\mathrm{min}$ ) was not consistent with that of UDP-MurNAc-L$\mathrm{Ala}(20 \mathrm{~min})$ (data not shown). It was presumably the result of the

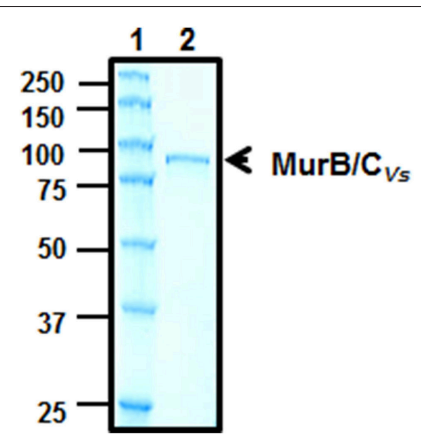

FIGURE 5 | Purification of MurB/C by affinity chromatography. Lane (1), protein ladder ( $\mathrm{kDa})$. Lane (2), $0.5 \mu \mathrm{g}$ of purified MurB/C. The proteins were resolved on a $10 \%(\mathrm{w} / \mathrm{v})$ acrylamide gel and stained with Coomassie blue for visualization.

direct addition of L-alanine to UDP-GlcNAc-EP, a reaction that has been shown to occur with E. coli MurC (Liger et al., 1995).

\section{Is MurB/ $\mathrm{C}_{V s}$ Active as a Fusion Enzyme in vivo?}

The SDS-PAGE showing the expression of the MurB/C $\mathrm{C}_{V s}$ in the murB and murC mutant backgrounds demonstrated that the recombinant enzyme was not cleaved in E. coli (Figure 4C). However, given the fact that there is a 100-residue linker region between the MurC and MurB domains (Figure 3), we were interested in answering the question of whether the fusion enzyme is cleaved in V. spinosum. This would indicate that after translation, the enzyme is processed by a protease to create two separate and distinct polypeptides of MurB and MurC. To answer this question, the purified recombinant enzyme (Figure 5) was used in a cleavage assay using crude soluble protein extract from $V$. spinosum. The assay showed that the recombinant enzyme was not cleaved when incubated with an extract from $V$. spinosum over a period of $120 \mathrm{~min}$ (Figure 6). It should be noted that the result was consistent when the assay was done using several concentrations of $V$. spinosum protein extract of up to $15 \mu \mathrm{g}$ and several buffer systems with varying $\mathrm{pH}$ values (data not shown). Based on the complementation, and supported by the cleavage assay, it is probable that the enzyme is active as a fusion enzyme in $V$. spinosum. Fusion enzymes involved in PG biosynthesis are not a new phenomenon; a MurC/Ddl fusion enzyme from Chlamydia trachomatis has been characterized and it was shown that the D-Ala:D-Ala ligase activity of the Ddl domain is dependent on the fusion structure of the MurC/Ddl protein (McCoy and Maurelli, 2005). Our present data show that at least the MurC domain of the $V$. spinosum MurB/C fusion protein is functionally independent as its expression allowed complementation of a temperature-conditional murC defect in E. coli.

\section{Unusual MurB and MurC Composition is Prevalent in the Currently Sequenced Members of Verrucomicrobia}

PhyloPhlAn-generated species tree of the PVC clade supports the monophyletic placement of the major lineage ( $\mathrm{SH}$-likelihood 


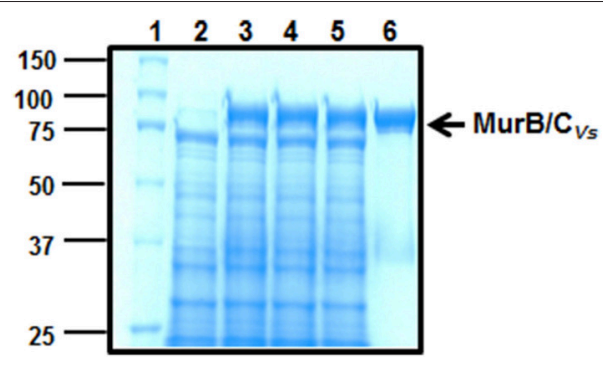

FIGURE 6 | Assay to assess cleavage of MurB/C using a crude protein extract from $\boldsymbol{V}$. spinosum. Lane (1), protein ladder (kDa). Lane (2), $15 \mu \mathrm{g}$ of $V$. spinosum extract. Lane (3), $15 \mu \mathrm{g}$ of $V$. spinosum extract plus $7.5 \mu \mathrm{g}$ of purified MurB/C at time zero. Lane (4), $15 \mu \mathrm{g}$ of $V$. spinosum extract plus 7.5 $\mu \mathrm{g}$ of purified MurB/C at $60 \mathrm{~min}$. Lane (5), $15 \mu \mathrm{g}$ of $V$. spinosum extract plus $7.5 \mu \mathrm{g}$ of purified MurB/C at $120 \mathrm{~min}$. Lane (6), $7.5 \mu \mathrm{g}$ of purified MurB/C. The temperature of the assay was $30^{\circ} \mathrm{C}$. The proteins were resolved on a $10 \%$ $(\mathrm{w} / \mathrm{v})$ acrylamide gel and stained with Coomassie blue for visualization.

branch support of $>0.90$ ). A slightly lower than average $\mathrm{SH}$-likelihood support value of 0.94 was observed in the branch splitting the Chlamydiae and Lentisphaerae clades which presumably is due to low taxon sampling $(N=1)$ of the Lentisphaerae clade (Figure 7A). Fused MurB/C is present in all the currently sequenced members of Verrucomicrobiales (9/9) and Methylacidiphilales (3/3). These members usually exhibit a conserved $f t s W$-murG-murB/C-ddlB-fts $Q$ gene organization (Figure 7B) with the exception of $V$. spinosum DSM 4138, the type species and type strain for the genus Verrucomicrobium and species $V$. spinosum, respectively. In $V$. spinosum DSM 4138 , the $m u r B / C$ gene is flanked by genes that are not directly related to cell-wall synthesis. However, the monophyletic grouping of MurB/C protein (including that of $V$. spinosum DSM 4138) suggests that fused $\mathrm{MurB} / \mathrm{C}$ is an authentic molecular signature in specific lineages of the phylum Verrucomicrobia and is not a result of inter-phylum horizontal gene transfer (Supplemental Figures 2A,B). TIGRFAM search failed to detect MurC domain in the predicted proteome from members of the class Opitutae (Figure 7A, green-colored branch). Despite lowering the detection threshold limit for MurC to the least stringent limit, e.g. noise cutoff, the MurC domain still could not be detected, thus supporting the absence of authentic MurC domain in this lineage. However, it is worth noting that the MurB proteins detected in nearly all members from Opitutae are longer than usual and contain the Mur ligase domain located at the N-terminal (Supplemental Figure 3 and data not shown), suggesting that although the $\mathrm{N}$-terminal region has diverged substantially from the typical MurC, it may still share partially overlapping function with MurC.

\section{DISCUSSION}

In the present paper, the in vivo MurB and MurC activities of the MurB/ $\mathrm{C}_{V s}$ fusion enzyme were revealed by functional complementation experiments. Furthermore, the protein was shown to be endowed with MurC ligase activity in vitro through a specific radioactive assay. In Table 3, the properties and kinetic parameters of the MurC ${ }_{V s}$ activity are compared with those of a reference ortholog (E. coli) and a phylogenetically related ortholog (C. trachomatis). The enzymes from V. spinosum and E. coli are comparable regarding their kinetic parameters. The maximum velocity of MurC $_{V s}$ is three-fold lower (but the $k_{c a t}$ value is only two-fold lower due to the high molecular mass of the fusion enzyme) when compared to the E. coli MurC. In addition, the optimal $\mathrm{pH}$ value (9.0) of the $\mathrm{MurC}_{V s}$ falls within the range found for most Mur ligases (8.0-9.2) (Patin et al., 2009) and the observed $\mathrm{pH}$ optimum is comparable to that of MurE from $V$. spinosum (9.6). It is possible that such values of $\mathrm{pH} \geq 9$ reflect environmental factors such as the natural habitat of $V$. spinosum (McGroty et al., 2013). On the other hand, MurC enzymes from $V$. spinosum and C. trachomatis have quite different kinetic parameters. The main difference is the maximum velocity, which is 75-fold lower for C. trachomatis MurC when compared to the MurC from $V$. spinosum. Although many reasons can be put forward to explain such a low maximum velocity, a physiological explanation might be related to the slower growth rate of $C$. trachomatis given the fact that it is an intracellular parasite (Hesse et al., 2003).

Although L-alanine is the best substrate in vitro, L-serine and glycine are also reasonable substrates (Table 4). From the in vitro data, the discrimination between the three amino acids in vivo is much less obvious than for MurC from E. coli (Liger et al., 1995). Nevertheless, the determination of the amino acid composition of PG from $V$. spinosum proves undoubtedly that L-Ala is the amino acid found at position 1 of the peptide stem (McGroty et al., 2013). With C. trachomatis MurC, the discrimination was even less obvious, since the three amino acids were added to UDP-MurNAc with similar $V_{\max } / K_{m}$ values, thereby preventing us from deducing which amino acid was present in the putative chlamydial PG (Hesse et al., 2003; Patin et al., 2012). The recent mass spectrometric detection, from C. trachomatis-infected cell lysates, of muropeptides with alanine or glycine at position 1 strongly suggests that these amino acid are both used as MurC substrates by C. trachomatis in vivo (Packiam et al., 2015).

While the MurC $_{V s}$ activity could be totally characterized, the $\operatorname{MurB}_{V s}$ activity could not be detected in vitro, even with the use of two different assays. Attempts to modify the assay conditions (different $\mathrm{pH}$ value, $\mathrm{NADH}$ instead of $\mathrm{NADPH}$ ) were unsuccessful. A plausible explanation for the lack of $\mathrm{MurB}_{V s}$ activity could be the denaturation of the MurB domain during or after the purification steps. Even though a cryoprotectant was included in the storage buffer, such a phenomenon cannot be ruled out. Another explanation would be that an unidentified cofactor(s) is necessary for activity which we are not aware of at this time. Nevertheless, the functional complementation of the $E$. coli $m u r B$ thermosensitive strain by the $m u r B / C_{V s}$ gene proves that the $\mathrm{MurB}_{V s}$ domain is active in in vivo conditions.

Based on phylogenetic and protein domain scanning, most members of the Verrucomicrobia possess different compositions of MurB and MurC proteins. In some lineages, both proteins are fused as is the case for $V$. spinosum. In others, the MurC seems to be absent. Given the phenotype of Verrucomicrobia regarding the unusual body plan with respect to wart-like and 
A

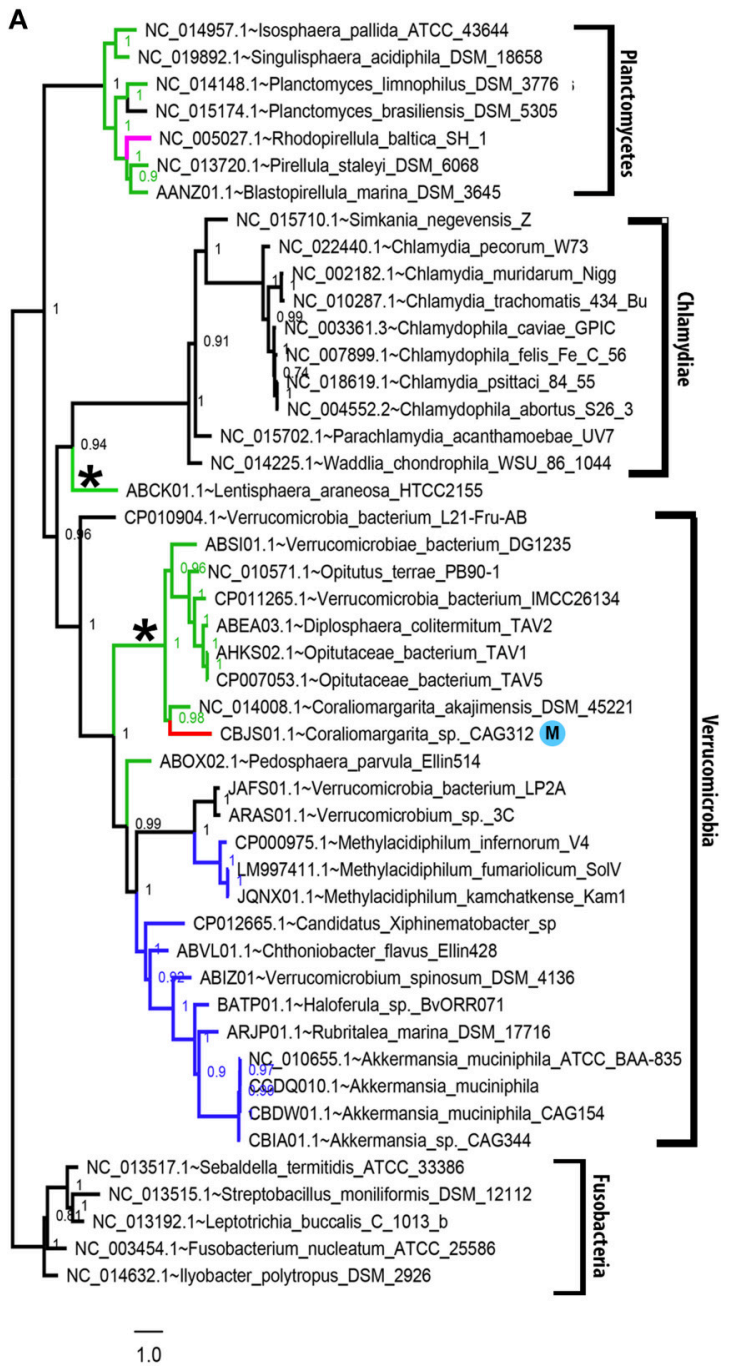

B

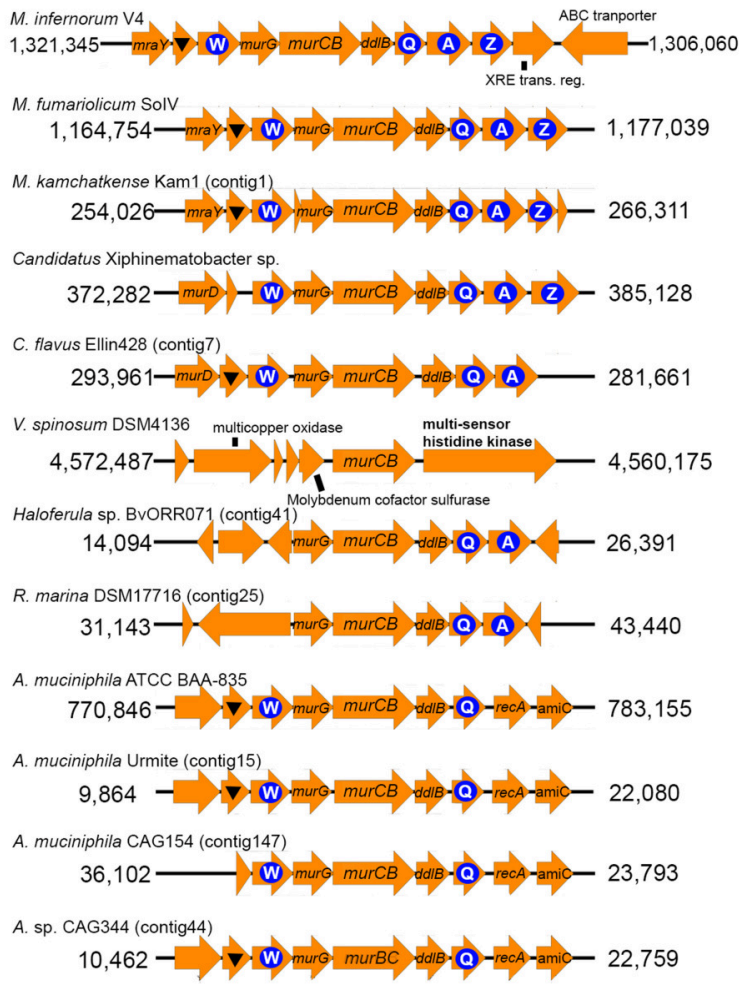

fumariolicum Solv

amchatkense Kam1 (contig1)

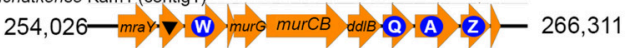

datus Xiphinematobacter sp.

(282-10

Us Ellin428 (contig7)

osum DSM4136 multicopper oxidase $\begin{aligned} & \text { multi-sensor } \\ & \text { histidine kinase }\end{aligned}-4,560,175$

Molybdenum cofactor sulfurase

$14,094-26,391$

31,143-

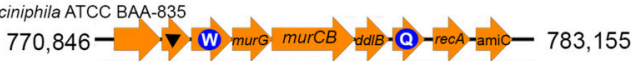

muciniphila Urmite (contig15)

iphila CAG154 (contig147)

$36,102-10$ murg murCB dalB-Q-recA-amic- 23,793

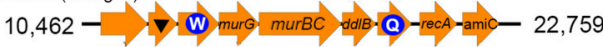

FIGURE 7 | (A) Species-tree of the Planctomycetes, Verrucomicrobia, and Chlamydiae (PVC) clade constructed using 400 universal proteins. Values next to each branch node represent SH-like branch supports as calculated by FastTree2 (Price et al., 2010). The scale bar indicates the number of substitutions per site. The tree was rooted with members from the phylum Fusobacteria as outgroup. Asterisk sign indicates lineage possessing a longer than usual MurB protein (>600 amino acid residues) and blue circle with the letter "M" indicates highly-fragmented genome that was derived from metagenomic assembly. The color designations for colored taxons are as follows: red for missing MurB and MurC, pink for missing MurC and MurB detected at slightly below the TIGR00179 trusted-cutoff score of 144.5 (142 $>\chi>144.5)$, green for missing MurC and blue for fused MurB/C. (B) Gene neighborhood of fused murB/C ORFs. Blue circle represents fts gene and letter within the circle represents the respective fts gene component. LysM-containing protein coding genes are indicated with a triangle and genes without label code for hypothetical proteins. Contig numbers are indicated next to species with draft genome sequence.

projections radiating from the central body, one would expect that PG biosynthesis would have an integral role pertaining to the shape of the bacterium (McGroty et al., 2013). Theoretically, the possession of a fusion protein that catalyzes sequential steps in a particular pathway may constitute an advantage when compared to a system where these orthologous proteins are separate. These advantages may include control of the expression of two genes as a single unit, substrate channeling due to proximity of the catalysts, higher catalytic activities, etc. Whether such an advantage, if it exists, influences growth and development of $V$. spinosum is currently not known. Further studies to determine the structure of the MurB/C fusion enzyme would help shed some light regarding the catalytic properties of the enzyme, especially since we were not able to demonstrate the MurB activity.

In summary, we present the first description of a MurB/C fusion enzyme from $V$. spinosum. In vitro biochemical analyses demonstrated that the enzyme is capable of catalyzing the ligase (MurC) reaction at position 1 on the peptide stem. In vitro analyses to demonstrate the MurB reductase were not successful even though in vivo analyses demonstrated that the fusion gene is able to functionally complement $E$. coli strains that harbor mutations in the murB and murC genes. Furthermore, dissection experiments showed that the MurB domain of the fusion protein was not essential for the UDP- $N$-acetylmuramate::L-alanine 
ligase activity of the MurC domain. As this is the first description of a MurB/C fusion enzyme, there are no structural studies in the literature. Therefore, studies to solve the structure of fusion enzymes such as MurB/ $\mathrm{C}_{V s}$ and MurC/Ddl from C. trachomatis would help elucidate properties of the enzyme and have the potential to provide information regarding the rational design and/or identification of compounds that are deemed inhibitory and that could be developed as antibiotics. As such, this study lays the foundation regarding the further understanding of the kinetic, physical, and structural properties of a novel enzyme involved in the synthesis of PG.

\section{AUTHOR CONTRIBUTIONS}

All authors listed, have made substantial, direct and intellectual contribution to the work, and approved it for publication.

\section{ACKNOWLEDGMENTS}

AH, KN, MW, and MS thank the Thomas H. Gosnell School of Life Sciences (GSOLS) and the College of Science (COS) at the Rochester Institute of Technology (RIT) for ongoing support. This work was supported by a Dean's Research Initiation (DRIG) awarded to AH by the COS at RIT. HG acknowledges the support from the Monash University Malaysia Tropical Medicine and Biology Multidisciplinary Platform. RD acknowledges the

\section{REFERENCES}

Barreteau, H., Kovač, A., Boniface, A., Sova, M., Gobec, A., and Blanot, D. (2008). Cytoplasmic steps of peptidoglycan biosynthesis. FEMS Microbiol. Rev. 32, 168-207. doi: 10.1111/j.1574-6976.2008.00104.x

Benson, T. E., Marquardt, J. L., Marquardt, A. C., Etzkorn, F. A., and Walsh, C. T. (1993). Overexpression, purification, and mechanistic study of UDP$\mathrm{N}$-acetylenolpyruvylglucosamine reductase. Biochemistry 32, 2024-2030. doi: 10.1021/bi00059a019

Bouhss, A., Dementin, S., van Heijenoort, J., Parquet, C., and Blanot, D. (2002). MurC and MurD synthetases of peptidoglycan synthesis: borohydride trapping of acyl-phosphate intermediates. Methods Enzymol. 354, 189-196.

Bouhss, A., Trunkfield, A. E., Bugg, T. D., and Mengin-Lecreulx, D. (2008). The biosynthesis of peptidoglycan lipid-linked intermediates. FEMS Microbiol. Rev. 32, 208-233. doi: 10.1111/j.1574-6976.2007.00089.x

Bradford, M. M. (1976). A rapid and sensitive method for the quantification of microgram quantities of protein utilizing the principle of protein dye binding. Anal. Biochem. 72, 248-254. doi: 10.1016/0003-2697(76) 90527-3

Capella-Gutiérrez, S., Silla-Martínez, J. M., and Gabaldón, T. (2009). trimAl: a tool for automated alignment trimming in large-scale phylogenetic analyses. Bioinformatics 25, 1972-1973. doi: 10.1093/bioinformatics/btp348

Cho, J. C., Vergin, K. L., Morris, R. M., and Giovannoni, S. J. (2004). Lentisphaera araneosa gen. nov., sp. nov, a transparent exopolymer producing marine bacterium, and the description of a novel bacterial phylum, Lentisphaerae. Environ. Microbiol. 6, 611-621. doi: 10.1111/j.1462-2920.2004.00614.x

Eddy, S. R. (2011). Accelerated profile HMM searches. PLoS Comput. Biol. 7:e1002195. doi: 10.1371/journal.pcbi.1002195

Falk, P. J., Ervin, K. M., Volk, K. S., and Ho, H. T. (1996). Biochemical evidence for the formation of a covalent acyl-phosphate linkage between UDP- $N$-acetylmuramate and ATP in the Escherichia coli UDP- $N$ acetylmuramate:L-alanine ligase-catalyzed reaction. Biochemistry 35, 1417-1422. doi: 10.1021/bi952078b following for funding support in part: (1) the Ministry of Business, Innovation, and Employment (contract UOCX1208), (2) the New Zealand Royal Society Marsden Fund (contract UOC1013), and (3) the US Army Research Laboratory and US Army Research Office under contract/grant number W911NF11-1-0481. This work was also supported by grants from the Centre National de la Recherche Scientifique (UMR 9198).

\section{SUPPLEMENTARY MATERIAL}

The Supplementary Material for this article can be found online at: http://journal.frontiersin.org/article/10.3389/fmicb. 2016.00362

\section{Supplemental Figure 1 | Growth of $E$. coli murC thermosensitive strain $\mathrm{H} 1119$ transformed by vector $\mathrm{pTrcHis60}(\mathrm{A}), \mathrm{p} \operatorname{TrcHis60::murC} \mathrm{Ec}_{E c}(\mathrm{~B})$, pTrcHis60::murC $V_{V^{-1}}-1$ (C), and pTrcHis60::murC $V_{V s}-2$ (D).}

Supplemental Figure 2 | Maximum likelihood tree of (A) MurB and (B) MurC proteins. Both trees are constructed using IQ-TREE version 1.3.10 with the optimized LG+G4 model. Value next to branch corresponds to IQ-TREE ultrafast bootstrap support value. Taxons containing fused MurB/MurC are colored red. The scale bar indicates the number of substitutions per site.

Supplemental Figure 3 | Complete InterProScan analysis of longer-than-usual MurB protein identified from the draft genome of Verrucomicrobiae bacterium DG1235 (accession number: ABSI01). The MurC domain corresponding to InterProScan ID IPR005758 (HAMAP: MF_00046; TIGRFAMs: TIGR01082) was absent from this MurB protein. However, domains corresponding to a general Mur ligase ( $\mathrm{N}$-terminal catalytic, central, and $\mathrm{C}$-terminal domains) are present in the $\mathrm{N}$-terminal region.

Finn, D., Bateman, A., Clements, J., Coggill, P., Eberhardt, R. Y., Eddy, S. R., et al. (2014). Pfam: the protein families database. Nucleic Acids Res. 42, D222-D230. doi: 10.1093/nar/gkt1223

Gubler, M., Appoldt, Y., and Keck, W. (1996). Overexpression, purification, and characterization of UDP- $N$-acetylmuramyl:L-alanine ligase from Escherichia coli. J. Bacteriol. 178, 906-910.

Guzman, L. M., Belin, D., Carson, M. J., and Beckwith, J. (1995). Tight regulation, modulation, and high level expression by vectors containing the arabinose pBAD promoter. J. Bacteriol. 177, 4121-4130.

Haft, D. H., Selengut, J. D., and White, O. (2003). The TIGRFAMs database of protein families. Nucleic Acids Res. 31, 371-373. doi: 10.1093/nar/ gkg128

Hesse, L., Bostock, J., Dementin, S., Blanot, D., Mengin-Lecreulx, D., and Chopra, I. (2003). Functional and biochemical analysis of Chlamydia trachomatis MurC, an enzyme displaying UDP- $N$-acetylmuramate: amino acid ligase activity. J. Bacteriol. 185, 6507-6512. doi: 10.1128/JB.185.22.6507-6512.2003

Hyatt, D., Chen, G. L., LoCascio, P. F., Land, M. L., Larimer, F. W., and Hauser, L. J. (2010). Prodigal: prokaryotic gene recognition and translation initiation site identification. BMC Bioinformatics 11:119. doi: 10.1186/1471-2105-11-119

Katoh, K., and Standley, D. M. (2013). MAFFT multiple sequence alignment software version 7: improvements in performance and usability. Mol. Biol. Evol. 30, 772-780. doi: $10.1093 / \mathrm{molbev} / \mathrm{mst} 010$

Liger, D., Masson, A., Blanot, D., van Heijenoort, J., and Parquet, C. (1995). Over-production, purification and properties of the uridine-diphosphate- $N$ acetylmuramate:L-alanine ligase from Escherichia coli. Eur. J. Biochem. 230, 80-87. doi: 10.1111/j.1432-1033.1995.0080i.x

Marchler-Bauer, A., Derbyshire, M. K., Gonzales, N. R., Lu, S., Chitsaz, F., Geer, L. Y., et al. (2015). CDD: NCBI's conserved domain database. Nucleic Acids Res. 43, D222-D226. doi: 10.1093/nar/gku1221

Marquardt, J. L., Siegele, D. A., Kolter, R., and Walsh, C. T. (1992). Cloning and sequencing of Escherichia coli murZ and purification of its product, a UDP- $N$-acetylglucosamine enolpyruvyl transferase. J. Bacteriol. 174, $5748-5752$. 
Matsuzawa, H., Matsuhashi, M., Oka, A., and Sugino, Y. (1969). Genetic and biochemical studies on cell wall peptidoglycan synthesis in Escherichia coli K-12. Biochem. Biophys. Res. Commun. 36, 682-689. doi: 10.1016/0006291X(69)90360-X

McCoy, A. J., and Maurelli, A. T. (2005). Characterization of Chlamydia MurCDdl, a fusion protein exhibiting D-alanyl-D-alanine ligase activity involved in peptidoglycan synthesis and D-cycloserine sensitivity. Mol. Microbiol. 57, 41-52. doi: 10.1111/j.1365-2958.2005.04661.x

McGroty, S. E., Pattaniyil, D. T., Patin, D., Blanot, D., Ravichandran, A. C., Suzuki, H., et al. (2013). Biochemical characterization of UDP-Nacetylmuramoyl-L-alanyl-D-glutamate: meso-2,6-diaminopimelate ligase (MurE) from Verrucomicrobium spinosum DSM 4136(T.). PLoS ONE 8:e66458. doi: 10.1371/journal.pone.0066458

Miyakawa, T., Matsuzawa, H., Matsuhahi, M., and Sugino, Y. (1972). Cell wall peptidoglycan mutants of Escherichia coli K-12: existence of two clusters of genes, $m r a$ and $m r b$, for cell wall peptidoglycan synthesis. J. Bacteriol. 112, 950-958.

Nachar, V. R., Savka, F. C., McGroty, S. E., Donovan, K. A., North, R. A., Dobson, R. C. J., et al. (2012). Genomic and biochemical analysis of the diaminopimelate and lysine biosynthesis pathway in Verrucomicrobium spinosum: identification and partial characterization of L,L-diaminopimelate aminotransferase and UDP- $N$-acetylmuramoylalanyl-D-glutamyl-2,6-meso-diaminopimelate ligase. Front. Microbiol. 3:183. doi: 10.3389/fmicb.2012.00183

Nguyen, L. T., Schmidt, H. A., von Haeseler, A., and Minh, B. Q. (2014). IQTREE: A fast and effective stochastic algorithm for estimating maximum likelihood phylogenies. Mol. Biol. Evol. 32, 268-274. doi: 10.1093/molbev/ msu300

Packiam, M., Weinrick, B., Jacobs, W. R. Jr., and Maurelli, A. T. (2015). Structural characterization of muropeptides from Chlamydia trachomatis peptidoglycan by mass spectrometry resolves "chlamydial anomaly". Proc. Natl. Acad. Sci. U.S.A. 112, 11660-11665. doi: 10.1073/pnas.1514026112

Park, J. T. (1987). "Murein synthesis," in Escherichia coli and Salmonella typhimurium: Cellular and Molecular Biology, Vol. 1, eds F. C. Neidhardt, J. L. Ingraham, K. B. Low, B. Magasanik, M. Schaechter, and H. E. Umbarger (Washington, DC: American Society for Microbiology), 663-671.

Patin, D., Bostock, J., Blanot, D., Mengin-Lecreulx, D., and Chopra, I. (2009). Functional and biochemical analysis of the Chlamydia trachomatis ligase MurE. J. Bacteriol. 191, 7430-7435. doi: 10.1128/JB.01029-09

Patin, D., Bostock, J., Chopra, L., Mengin-Lecreulx, D., and Blanot, D. (2012). Biochemical characterization of the chlamydial MurF ligase, and possible sequence of the chlamydial peptidoglycan pentapeptide stem. Arch. Microbiol. 194, 505-512. doi: 10.1007/s00203-011-0784-8

Pilhofer, M., Aistleitner, K., Biboy, J., Gray, J., Kuru, E., Hall, E., et al. (2013). Discovery of chlamydial peptidoglycan reveals bacteria with murein sacculi but without FtsZ. Nat. Commun. 4:2856. doi: 10.1038/ ncomms 3856

Pompeo, F., van Heijenoort, J., and Mengin-Lecreulx, D. (1998). Probing the role of cysteine residues in glucosamine-1-phosphate acetyltransferase activity of the bifunctional GlmU protein from Escherichia coli: Site-directed mutagenesis and characterization of the mutant enzymes. J. Bacteriol. 180, 4799-4803.

Press, W. H., Flannery, B. P., Teukolsky, S. A., and Vetterling, W. T. (1986). Numerical Recipes: The Art of Scientific Computing. Cambridge: Cambridge University Press.
Price, M. N., Dehal, P. S., and Arkin, A. P. (2010). FastTree 2 - approximately maximum-likelihood trees for large alignments. PLoS ONE 5:e9490. doi: 10.1371/journal.pone.0009490

Pucci, M. J., Discotto, L. F., and Dougherty, T. J. (1992). Cloning and identification of the Escherichia coli murB DNA sequence, which encodes UDP$N$-acetylenolpyruvoylglucosamine reductase. J. Bacteriol. 174, 1690-1693.

Sait, M., Kamneva, O. K., Fay, D. S., Kirienko, N. V., Polek, J., Shirasu-Hiza, M. M., et al. (2011). Genomic and experimental evidence suggests that Verrucomicrobium spinosum interacts with eukaryotes. Front. Microbiol. 2:211. doi: 10.3389/fmicb.2011.00211

Scheffers, D. J., and Pinho, M. G. (2005). Bacterial cell wall synthesis: new insights from localization studies. Microbiol. Mol. Biol. Rev. 69, 585-607. doi: 10.1128/MMBR.69.4.585-607.2005

Schleifer, K. H., and Kandler, O. (1972). Peptidoglycan types of bacterial walls and their taxonomic implications. Bacteriol. Rev. 36, 407-477.

Schlesner, H. (1987). Verrucomicrobium spinosum gen. nov., sp. nov.: a fimbriated prosthecate bacterium. Syst. Appl. Microbiol. 10, 54-56. doi: 10.1016/S07232020(87)80010-3

Segata, N., Börnigen, D., Morgan, X. C., and Huttenhower, C. (2013). PhyloPhlAn is a new method for improved phylogenetic and taxonomic placement of microbes. Nat. Commun. 4, 2304. doi: 10.1038/ncomms3304

Sullivan, M. J., Petty, N. K., and Beatson, S. A. (2011). Easyfig: a genome comparison visualizer. Bioinformatics 27, 1009-1010. doi: 10.1093/bioinformatics/btr039

Tayeh, M. A., Dotson, G. D., Clemens, J. C., and Woodard, R. W. (1995). Overproduction and one-step purification of Escherichia coli UDP-Nacetylglucosamine enolpyruvyl reductase. Protein Expr. Purif. 6, 757-762. doi: 10.1006/prep.1995.0006

Vollmer, W., Blanot, D., and de Pedro, M. A. (2008). Peptidoglycan structure and architecture. FEMS Microbiol. Rev. 32, 149-167. doi: 10.1111/j.15746976.2007.00094.x

Wagner, M., and Horn, M. (2006). The Planctomycetes, Verrucomicrobia, Chlamydiae and sister phyla comprise a superphylum with biotechnological and medical relevance. Curr. Opin. Biotechnol. 17, 241-249. doi: 10.1016/j.copbio.2006.05.005

Wanke, C., Falchetto, R., and Amrhein, N. (1992). The UDP-N-acetylglucosamine 1-carboxyvinyl-transferase of Enterobacter cloacae. Molecular cloning, sequencing of the gene and overexpression of the enzyme. FEBS Lett. 301, 271-276. doi: 10.1016/0014-5793(92)80255-F

Wijsman, H. J. (1972). A genetic map of several mutations affecting the mucopeptide layer of Escherichia coli. Genet. Res. 20, 65-74. doi: $10.1017 /$ S0016672300013598

Conflict of Interest Statement: The authors declare that the research was conducted in the absence of any commercial or financial relationships that could be construed as a potential conflict of interest.

Copyright (C) 2016 Naqvi, Patin, Wheatley, Savka, Dobson, Gan, Barreteau, Blanot, Mengin-Lecreulx and Hudson. This is an open-access article distributed under the terms of the Creative Commons Attribution License (CC BY). The use, distribution or reproduction in other forums is permitted, provided the original author(s) or licensor are credited and that the original publication in this journal is cited, in accordance with accepted academic practice. No use, distribution or reproduction is permitted which does not comply with these terms. 